\title{
Dossiê Especial \\ Migrações Internacionais e o Direito à Educação: \\ Desafios para o Enfrentamento de Desigualdades pelas Políticas dos \\ Sistemas de Ensino
}

\section{arquivos analíticos de políticas educativas}

Revista acadêmica, avaliada por pares, independente, de acesso aberto, e multilíngue

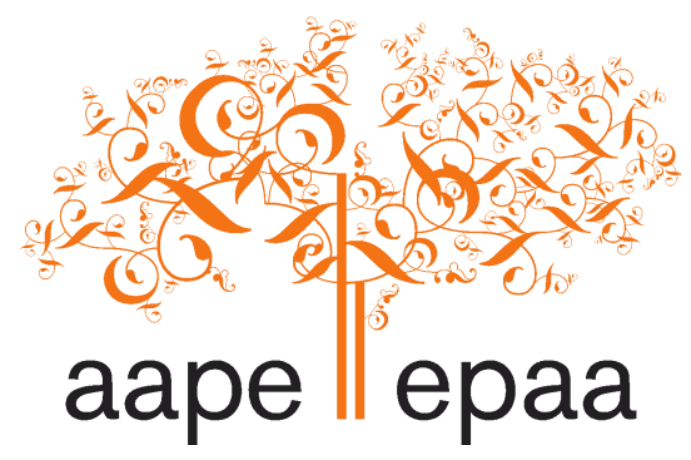

Arizona State University

\section{Imigração e Refúgio nos Debates e Políticas Educativas Globais: Uma Aproximação aos Discursos sobre as Mobilidades e seus Sujeitos}

\author{
Giovanna Modé Magalhães \\ \& \\ Flávia Schilling \\ Universidade de São Paulo \\ Brasil
}

Citação: Magalhães, G. M., \& Schilling, F. (2021). Imigração e refúgio nos debates e políticas educativas globais: Uma aproximação aos discursos sobre as mobilidades e seus sujeitos. Arquivos Analíticos de Políticas Educativas, 29(75). https://doi.org/10.14507/epaa.29.6268 Este artigo faz parte do dossiê especial, Migrações Internacionais e o Direito à Educação: Desafios para o Enfrentamento de Desigualdades pelas Políticas dos Sistemas de Ensino, editada por Ana Lorena de Oliveira Bruel, Isabelle Rigoni e Maïtena Armagnague.

Resumo: Os sistemas educativos, a partir da constatação da presença de imigrantes e refugiados nas escolas, sobretudo nas redes públicas de ensino, emergem como um campo de pesquisa, política e ação para entender os diferentes discursos a propósito das mobilidades contemporâneas. Neste trabalho, nossa preocupação residiu em perceber o quanto o debate e as políticas educativas globais - ainda que incipientes sobre a temática - interagiam, reforçavam ou contradiziam as distintas práticas, representações e dizeres que tomam as mobilidades e seus sujeitos por objeto de regulação e conhecimento. Buscamos observar os discursos que mobilizam, para fundamentalmente entender 
como se articulam ao paradigma da migração como um problema a combater-se - e não como um dado constitutivo do mundo. Como estratégia metodológica, optamos pela análise de um conjunto recente de documentos orientadores de políticas educativas de alcance global que tratassem de imigração e refúgio, de autoria de organismos internacionais das Nações Unidas. Neste conjunto, destacamos dois aspectos centrais para reflexão: de maneira mais ampla o tratamento dado aos sujeitos individuais e coletivos das mobilidades, e um segundo eixo focado especificamente na maneira como se constrói e se reforça a "figura da vítima", bem como suas implicações, tensões e ambiguidades.

Palavras-chave: políticas educacionais; discursos; imigração; refúgio

\section{Migration and asylum in global education policies and debates: An approach to the discourses on mobilities and its subjects}

Abstract: Considering the increased presence of immigrants and refugees in schools, particularly public schools, educational systems emerge as a field of research, policy and practice to understand the different discourses regarding contemporary mobilities. In this piece of work, our concern was to understand on which extension global education policies and debates, even being incipient on this matter, interact, reinforce or contradict the different practices, representations and sayings that make mobilities and their subjects an object of regulation and knowledge. We seek to observe the mobilized discourses, in order to fundamentally understand how they are articulated to the paradigm of global migration "as a problem" to overcome, instead of a constitutive characteristic of the world. As methodological strategy, we analyzed a recent set of documents guiding educational policies that deals with migration and asylum, written by different United Nations agencies. From this set, we highlight two central aspects for reflection: in a broader way the treatment given to individual and collective subjects of mobilities, and as a second axis we focused on the way the "figure of the victim" is built and reinforced, as well as its implications, tensions and ambiguities.

Keywords: educational policies; discourses; immigration; refugees

\section{Inmigración y refugio en las políticas y debates educativos globales: Una aproximación a los discursos sobre las movilidades y sus sujetos}

Resumen: Los sistemas educativos, a partir de la presencia de inmigrantes y refugiados en las escuelas, especialmente en las escuelas públicas, emergen como un campo de investigación, política y acción para comprender los diferentes discursos sobre las movilidades contemporáneas. En este trabajo, nuestra preocupación estuvo en conocer cuánto las políticas y el debate educativo global aunque incipiente sobre el tema - interactúan, refuerzan o contradicen las distintas prácticas y representaciones que hacen de las movilidades y sus sujetos objeto de regulación y conocimiento. Buscamos observar los discursos que movilizan, para entender fundamentalmente cómo se articulan al paradigma de las migraciones internacionales como un problema a combatirse - y no como un dato constitutivo del mundo. Como estrategia metodológica, se optó por el análisis de un conjunto reciente de documentos que orientan las políticas educativas de alcance global que abordan la inmigración y el refugio, elaborado por diferentes agencias de Naciones Unidas. En este conjunto, destacamos dos aspectos centrales de reflexión: de forma más amplia el tratamiento que se da a los sujetos individuales y colectivos de la movilidad, y un segundo eje centrado específicamente en la forma en que se construye y se refuerza la "figura de la víctima", así como como sus implicaciones, tensiones y ambigüedades.

Palabras-clave: políticas educativas; discursos; inmigración; refugio 


\section{Imigração e Refúgio nos Debates e Políticas Educativas Globais: Uma Aproximação aos Discursos sobre as Mobilidades e seus Sujeitos}

O cruzar fronteiras passou a ser visto como um dos grandes desafios que interpelam as democracias (Herrera, 2009), enquanto pessoas, coletivos, famílias, no mundo todo, seguem resistindo e construindo projetos de vida em circulação, como sempre fizeram. As inúmeras tentativas de controlar as populações em movimento - contendo as não autorizadas e estimulando as desejadas - passa hoje pelas discussões mais contemporâneas sobre poder, governo e biopolítica. São processos pelos quais perpassam lógicas múltiplas de desigualdade e discriminação (Castles, 2010), assim como jogos de governo e controle (Fassin, 2011), configurando um campo tenso que constrói e aclama a mobilidade internacional como símbolo de uma sociedade aberta e moderna, ao mesmo tempo em que desenvolve mecanismos de repulsão àquela migração que não é bem-vinda.

Entre os muitos fragmentos que compõem esse campo de observação estão os sistemas educativos: a partir da constatação da presença de imigrantes e refugiados nas escolas, sobretudo nas redes públicas de ensino, emerge um campo de pesquisa, política e ação. Bartlett (2015) afirma que tanto as políticas educativas, como os discursos que se produzem no interior de cada escola, configuram-se como lugares privilegiados para a observação das lógicas sociais, políticas e econômicas que constroem as relações de poder e governo - incluindo aquelas relacionadas às mobilidades humanas. Ao mesmo tempo, a educação em si é um lugar essencial na produção e reprodução, também um campo de luta e de contestação contínua (Giroux, 1995), porque se molda na intersecção entre reprodução social e cultural, por um lado, e rupturas por meio de práticas alternativas e desestabilizadoras, por outro, ou seja, é ali também um lugar onde podem surgir resistências, novos discursos e narrativas.

Assim, neste trabalho nossa preocupação residiu em perceber o quanto as políticas e o debate educativo global - ainda que incipiente sobre a temática - interagiam, reforçavam ou contradiziam as distintas práticas, representações e dizeres que tomam as mobilidades e seus sujeitos por objeto de regulação e conhecimento. Entendemos que a disseminação e o reforço na representação, estática e hierárquica, sobre os chamados de estrangeiros, ocorre através de um imensurável emaranhado discursivo no qual interagem vozes vindas das políticas públicas e instituições, das representações jurídicas, escolares, socioassistenciais, sanitárias, dos meios de comunicação, das percepções do dia a dia e inclusive de pesquisas acadêmicas (Bartlett, 2015; Santamaría, 2002).

Aqui, nos deteremos a dois aspectos que nos parecem centrais para a abordagem dos debates migratórios, buscando perceber como são construídos também no campo das políticas educativas globais: um primeiro relacionado mais amplamente à nomeação dos sujeitos das mobilidades, e um segundo focado especificamente no reforço à construção da figura da vítima, dinâmica articulada a um discurso em torno a uma "crise", repleto de tensões e ambiguidades como veremos mais adiante.

Nos interessa observar os discursos que mobilizam, para fundamentalmente entender como se articulam ao paradigma discursivo da migração como um problema a combater-se - e não como um dado constitutivo do mundo. É notável a prevalência de enfoques que tratem dos fluxos migratórios como um problema social, que gera ou exacerba também problemas de ordem pública (de acesso a serviços de educação, saúde, moradia etc), ao qual as políticas e governos devem responder (Santamaría, 2002). A observação dessa dinâmica revela sobretudo a necessidade de recuperar outros lugares de visão que ampliem sua narrativa, que mostrem outras formas e possibilidades de falar sobre as mobilidades humanas, extrapolando seu tratamento como um problema ou ameaça. 


\section{Enfoque Metodológico}

Como estratégia metodológica, optamos pela leitura e análise de um conjunto de documentos de alcance global, documentos ao mesmo tempo analíticos e orientadores para educação, que abordam a temática da imigração e refúgio. Selecionamos peças específicas com alcance e circulação globais, que de alguma maneira se difundem com facilidade pela autoria institucional que possuem ${ }^{1}$. Ainda que pretendam abranger um número amplo de atores sociais, em geral são voltados a gestores públicos, sobretudo de ministérios de educação, mas também aos pares de outras agências multilaterais e organizações da sociedade civil que disputam visões e concepções nos espaços de política educativa em âmbito global.

Trata-se de um conjunto recente, dado que impõe desafios para uma leitura distanciada. No início dos anos 2000, eram poucos e específicos os materiais que empreendiam o esforço de falar de educação e imigração ou refúgio no âmbito global. Uma década e meia mais tarde, o acervo disponível nas agências internacionais, sejam do sistema ONU, agências multilaterais ou ONGs com presença em diversos países, proliferou-se notavelmente. Para este estudo, selecionamos documentos com autorias sempre institucionais que incluem agências de cooperação (OCDE, ACNUR, UNICEF, UNESCO) e peças de autoria conjunta entre estas mesmas agências, ONGs ou setor privado ${ }^{2}$. Importante notar que se tratam de instituições particulares, com históricos, propósitos e objetivos distintos, mas cuja produção recente sobre a temática da educação, imigração e refúgio resulta num conjunto que nos oferece a possibilidade de reconhecer algumas linhas discursivas convergentes. Incluímos também, de maneira complementar, documentos de autoria coletiva, como é o caso do Marco de Ação da Educação $2030^{3}$ - por refletir muito dos debates globais sobre educação na atualidade. Para além de tratarem do tema da educação para pessoas migrantes e refugiadas, as principais características em comum a esta seleção são o pretendido alcance global, a natureza de construir e disputar agendas e o intento de influenciar os sistemas nacionais de educação.

A leitura de cada um foi realizada de maneira porosa para outras peças disponíveis, e em paralelo com outros textos, não só referências teóricas do campo das mobilidades e Ciências Sociais,

\footnotetext{
${ }^{1}$ Em geral são produzidos em inglês, e alguns são traduzidos a diversos outros idiomas para alcançarem circulação em um número maior de países. Todos estão disponíveis online e a maioria sem custos. $\mathrm{O}$ conjunto que utilizamos está acessível nas páginas web institucionais das respectivas organizações. ${ }^{2}$ De agências das Nações Unidas: Marco de Ação da Educação 2030 (UNESCO, 2015), Migração, deslocamento e educação: construir pontes, não muros (UNESCO, 2018), Left Behind-Refugee Education in Crises (ACNUR, 2017), 2012-2016 Education Strategy (ACNUR, 2012), Refugee Education: Global Review (ACNUR, 2011), Unfairly Tales (UNICEF, 2016), Uprooted: The growing crisis for refugee and migrant children (UNICEF, 2018), Education Uprooted: for every migrant, refugee or displaced child, education (UNICEF, 2017); de outros organismos multilaterais: The resilience of Students with Migrant Background, Factors that Shape Well Being (OCDE, 2018); e finalmente de parcerias entre Nações Unidas e outros atores, ONGs e setor privado, como foi o caso do conjunto de documentos Best practices in refugees education, case studies (Save the Children, ACNUR, Pearsons, 2017).

3 Peça importante elaborada no ano de 2015 como forma de ampliar a narrativa do Objetivo de Desenvolvimento Sustentável N. 4 acordado no âmbito da Agenda 2030 ("Assegurar a educação inclusiva e equitativa e de qualidade, e promover oportunidades de aprendizagem ao longo da vida para todas e todos"). Foi resultado de muitos debates, consultas e negociações, entre governos, organizações internacionais e sociedade civil, para ser posteriormente adotada pelos conjunto de Estados. Seu processo de elaboração foi coordenado pela UNESCO, mas envolveu outros 7 organismos: UNICEF, Banco Mundial, UNFPA, PNUD, ONU Mulheres. OIT e o ACNUR.
} 
mas também ao lado de uma série de documentos institucionais e políticos ${ }^{4}$ que circulam sobre a temática, além de colocados em diálogo com a cobertura mediática, em si mesma responsável pela criação de imagens e representações a propósito das mobilidades e sobretudo de seus sujeitos (Cogo, 2013; OIM, 2018) ${ }^{5}$.

Fundamentalmente, não faz parte do escopo de nossa pesquisa avaliar o projeto, documento ou política em questão como uma peça singular. Nosso esforço é o de identificar as possíveis leituras de como constroem o diálogo entre imigração e educação e sobretudo como aparece a figura do sujeito que migra, como vem a ser. Nosso entendimento é de que se tratam de atores políticos relevantes no plano global, e que seu discurso, como muitos outros, gera efeitos.

Gildersleeve (2016) explica que política e discursos interagem e, portanto, examinar essa interação é examinar os exercícios de poder e seus efeitos materiais plausíveis - incluindo a produção de sujeitos. Recorre-se à perspectiva foucaultiana de que o discurso produz realidade e o poder opera discursivamente. Ou, o discurso se apoia no poder para produzir significados na vida cotidiana. O poder não é uma possessão, mas um exercício. O poder circula pelo caminho do discurso entre e por meio das relações sociais. Opera no nível local e a transformação ocorre a partir de uma infinidade de negociações e discursos inter relacionados. Assim, a relação saber/poder se dá no âmbito discursivo, e a verdade seria o efeito dessa operação, necessariamente fraturada e incompleta. Portanto verdades são produzidas, nunca estáveis, e sempre com fronteiras históricas.

\section{Antecedentes Históricos: Imigração e Refúgio na Política Educativa Global}

Foi em meados do século XX que a educação tornou-se um tema entre as preocupações globais, passando a estar na arena dos gestores (policy makers) e organizações internacionais. Até então, se bem os sistemas educativos já eram vistos como um aparato fundamental dos Estados ocidentais modernos - com notórias preocupações como a expansão do acesso à escolarização elementar, alocação orçamentária para educação, estabelecimento de currículos e de corpo docente e estrutura para o apoio àquilo que Anderson (2008) descreve como "comunidade imaginada" do Estado-nação na modernidade -, os esforços concentravam-se eminentemente no âmbito nacional. As preocupações e iniciativas globais eram pontuais e experimentais, como foi o caso da criação do Bureau de Educação Internacional na Liga das Nações (Mundy et al., 2016).

Os marcos iniciais foram a formação da UNESCO, criada em 1945 com o mandato para a promoção da educação no mundo, e a adoção da própria Declaração Universal de Direitos Humanos de 1948, que então posiciona a educação na agenda de um novo tipo de multilateralismo no pós guerra. A partir daquele momento, proliferam-se esforços multi e bilaterais, governamentais e não governamentais, para influenciar os sistemas educacionais a afirmarem parâmetros globais de educação. Como pontuam Mundy et al. (2016), nas décadas seguintes o fim do regime colonial e o

${ }^{4}$ Em particular discursos proferidos e registrados no United Nations Summit for Refugees and Migrants em 19 de setembro de 2016, cúpula das Nações Unidas convocada para tratar do tema considerado "objeto de crise atual".

${ }^{5}$ O Relatório Global de Migrações 2018, publicado pela OIM, atribui particular importância ao papel da mídia no estabelecimento das imagens negativas de imigrantes nos países receptores, afirmando que a cobertura mediática pode afetar também a auto percepção e como os e as imigrantes relacionam-se com os países anfitriões. Podem também influenciar as decisões de migrar. Em síntese, as mensagens influenciam todo o ciclo migratório. O reconhecimento dessa influência levou organizações de diversos países a organizarem campanhas por imagens positivas, como I am a migrant (disponível em http://www.iamamigrant.org/) ou Refugees are welcome (disponível em http://www.refugeesarewelcome.org/). 
estabelecimento de novos Estados depois da Segunda Guerra igualmente fomentam a preocupação com uma política de educação global.

Nos anos 60, uma das expressões dessa preocupação é a incorporação do tema educativo por novas agências e organismos, como UNICEF e Banco Mundial, sobretudo com ênfase nos países africanos que recém ficavam independentes. Posteriormente, num contexto em que predominava a ideia de desenvolver a economia de maneira mais integrada, cujo símbolo seria o acordo de Bretton Woods aliado ao discurso de mais liberdades políticas e civis, a educação passa a ser vista, nesses espaços, como um importante instrumento para a paz duradoura e para a prosperidade, algo relevante nos esforços multilaterais que se consolidavam. A partir dos anos 70, o movimento de desregulação financeira, o notável crescimento de corporações transnacionais e da chamada economia global, tem efeitos notáveis na educação e sobretudo na construção da ideia de "capital humano", marcada por uma matriz reducionista do propósito educativo, que subordina o processo educativo às necessidades de um mercado de trabalho a serviço do crescimento econômico.

Mais recentemente, a chamada comunidade internacional da educação passa a caracterizar-se por uma complexidade muito relevante, incluindo atores multilaterais como OCDE, G8, Banco Mundial, Organização Mundial do Comércio (OMC), organizações regionais, além de atores não estatais em campos políticos por vezes antagônicos, redes da sociedade civil, ONGs internacionais, sindicatos de professores, movimentos sociais e também setor privado, sobretudo fundações empresariais, que cada vez mais fortalecem sua presença na construção dos espaços de definição de políticas globais (Croso \& Magalhães, 2015). Esse conjunto, ainda que disperso e fragmentado, vem pautando e disputando temas na agenda educativa, com notável influência nas pesquisas e também nas políticas públicas.

Longe de terem uma influência determinante e uniforme, sabe-se que os processos e políticas globais não circulam de maneira previsível. São negociações diferentes em cada contexto ou território, onde instituições e atores locais interagem e negociam. E a circulação mais latente de ser observada é no campo discursivo, ainda que sua assunção no âmbito interno continue fortemente mediada. Ball (2001) define ciclo político como as relações multi-direcionais e não lineares ao longo do processo de construção da agenda, produção do texto da política e sua promulgação. Usa o termo promulgação (enactment) ao invés de implementação para destacar como a agência e o envolvimento de uma variedade de atores no âmbito global, nacional, sistêmico e institucional modificam políticas já que incluem a construção do discurso e também a prática. Em definitivo, há uma expressão desigual do discurso da política global no âmbito nacional ou local e por outro lado uma recontextualização e uma transformação drástica de tais ideias globais dentro das instituições locais, redes, práticas.

Ao longo dessa trajetória de debates globais, a educação para populações imigrantes e refugiadas sempre teve valor marginal. A partir da segunda metade do século XX, a UNESCO, como dissemos criada ao final da Segunda Guerra Mundial com o mandato para a educação, mantinha o diálogo com os Estados Nacionais para que estes desenvolvessem políticas estratégicas para suas respectivas populações, nas quais os não nacionais não eram vistos como parte relevante. Nesse caso, a responsabilidade passa para o ACNUR, que embora não cuidasse dos temas educativos, era a agência que estava mais próxima dos crescentes grupos de refugiados que se faziam visíveis no contexto do pós-guerra (Dryden-Peterson, 2016).

Nas décadas que se seguiram, o ACNUR passou então a desenvolver e apoiar experiências práticas sem necessariamente uma linha condutora ou uma política educativa - apoiava, por exemplo, ações educativas auto-organizadas pelas próprias comunidades refugiadas, em geral experiências de educação não formal, bem como buscava recursos com organizações filantrópicas 
para que parte das pessoas refugiadas pudesse estudar em níveis equivalentes ao Ensino Médio. Ao mesmo tempo, organizações da sociedade civil empreendiam esforços de oferecer escolas para deslocados de guerra, em geral de maneira desarticulada de qualquer sistema educativo ${ }^{6}$.

No final dos anos 80 e início dos 90 é que a educação para pessoas deslocadas ganha novos contornos em âmbito global - aqui majoritariamente referindo-se ainda às populações refugiadas. Educação para pessoas migrantes não era, ao menos com essa terminologia, uma preocupação, apenas as ações voltadas à crescente população que se deslocou de maneira forçada emergia como um tema que requeria resposta dos Estados. De ações pontuais, passa-se, ainda que timidamente, a falar-se em esforços para a integração das populações refugiadas nos sistemas nacionais de educação ou na necessidade de planos estratégicos de educação especificamente voltados aos refugiados ${ }^{7}$.

Várias razões contribuíram para esse deslocamento, entre elas a ratificação de um conjunto de novos instrumentos de Direitos Humanos, como a Convenção dos Direitos das Crianças em 1989, o aumento massivo do fluxo de deslocados, e a realização de conferências mundiais para que fossem traçadas metas de educação com os governos, como foi o caso da realização das três grandes conferências mundiais para o estabelecimento de acordos de "educação para todos": em 1990 (Jomtien, Tailandia), em 2000 (Dakar, Senegal) e mais recentemente em 2015 (Incheon, Coreia do Sul) - este último já articulado aos esforços no âmbito da Agenda 2030 de Desenvolvimento Sustentável.

Ao longo destes debates, emergiam as desigualdades na realização do direito à educação, e entre elas a exclusão sistemática das populações refugiadas no âmbito dos sistemas educativos. Em que pese a escassez ou inconsistência das estatísticas nessa área, os dados estimavam, em $2017^{8}$, que 61\% das crianças refugiadas estavam matriculadas nos níveis primários (enquanto a média mundial é de $91 \%$ ) e apenas 23\% nos níveis secundários (ante a média mundial de $74 \%$ ). Sobretudo nos países com quantidades significativas de pessoas refugiadas ou em regiões fronteiriças, a entrada dessas populações nos sistemas nacionais de ensino, em todo caso, continua sendo um tema de difícil consenso, pois gera um custo maior que os governos relutam em assumir. Portanto tradicionalmente a oferta educativa foi sendo realizada pela ajuda humanitária através de sistemas paralelos, fragmentados e inconstantes. O debate recente deixa evidente que não se trata de solução sustentável, mas na prática ainda persiste como alternativa.

Ao mesmo tempo, é também a partir dos anos 1990 que começa a consolidar-se, no âmbito internacional, a chamada área de educação em contextos de emergências, ou educação em conflitos, que envolve como agentes de pesquisa e intervenção um amplo leque de atores. Desde então, nas poucas vezes em que se fala em educação e refugiados nos debates globais sobre educação, é nesse contexto que aparece: atrelada ao contexto de conflitos e emergências - portanto tangenciando também as agendas de segurança internacionais. Era como se a educação das pessoas refugiadas tivesse encontrado um lugar que lhe coubesse na agenda global que trata da educação - lembrando que até então era renegada ao completo desinteresse, mal era mencionada, não encontrava atenção dos atores mais significativos, nem de Estados nem da comunidade internacional.

Nesse sentido, Novelli \& Cardoso (2008) chamam a atenção para a necessidade de um olhar mais atento sobre a relação entre educação, conflitos, cooperação internacional e direitos humanos.

${ }^{6}$ Esforços comunitários também foram registrados, como dos exilados da Eritreia no Sudão em 1970, nicaraguenses em Honduras nos anos de 1980, ou processos ligados aos movimentos pelo fim do colonialismo, como o caso registrado pela autora sobre o Colégio pela Liberdade Solomon Mahlangu, do Congresso Nacional Africano, na Tanzânia (Dryden-Peterson, 2016).

${ }^{7}$ História institucional do ACNUR detalhadamente narrada em Dryden-Peterson (2011).

${ }^{8}$ Dados do ACNUR (2018), em comparação com as médias calculadas a partir dos dados do Informe UNESCO (2018). 
Nas situações de conflito, a presença internacional através da ajuda humanitária ou de agências multilaterais é uma constante e, diante disso, alertam para a lacuna de análises que relacionem os níveis locais, regionais e global. Existe um descompasso, dizem os autores, na medida em que os atores internacionais acabam tendo predominância e agem a partir de uma mistura de interesses humanitários, de desenvolvimento e de segurança internacional. E indagam, finalmente, se essa última não estaria tendo supremacia ${ }^{9}$. Interesses de promoção de direitos, dizem, nem sempre são compatíveis com interesses estratégicos geopolíticos, sugerindo que uma lacuna de pesquisa neste campo é a análise sobre quem é a chamada comunidade internacional que atua na educação, desmistificando sua aparente homogeneidade.

\section{Leituras e Reflexões sobre o Não Nacional}

Dado este breve contexto histórico sobre a presença da imigração e refúgio nas políticas educativas globais, nos interessa portanto olhar para a produção discursiva mais recente, tecendo reflexões sobre de que maneira constitui-se como mais um entre os muitos dispositivos que participam da construção discursiva sobre as mobilidades e seus sujeitos. Para isso, selecionamos, como foi dito em nossa introdução, dois eixos de reflexão para estabelecer o dialogo com o conjunto de documentos analisados: um primeiro vinculado ao tratamento dado aos sujeitos individuais e coletivos das mobilidades, como são nomeados e descritos, e um segundo focado especificamente na maneira como se constrói e se reforça a "figura da vítima".

\section{Mobilidades e seus Sujeitos: Sobre quem se Fala?}

Como um primeiro eixo analítico, buscamos entender quem é a pessoa e sobretudo o coletivo em mobilidade ao qual se refere o conjunto documental analisado, como aparecem, como são descritos, como se fala sobre eles.

$\mathrm{Na}$ própria literatura sobre mobilidades internacionais, as mais variadas formas de nomear os sujeitos do percurso migratório conformam um ponto revelador das disputas e tensões ao redor do tema, sendo a naturalização da divisão mais tradicional entre migrações voluntárias ou forçadas em si mesma objeto de reflexão. As primeiras são em geral apresentadas como resultados do desejo, enquanto as segundas são caracterizadas pela coerção e violência. No entanto, como lembram Bertino \& Sala (2018), "pode haver desejo em processos migratórios caracterizados como compulsórios, ao mesmo tempo em que se verifica violência também nos fluxos tidos como voluntários" (Bertino \& Sala, 2018, p. 16). Nesse mesmo sentido, Mezzadra (2015) lembra do autor indiano Ranabir Samaddar, entre outros, que insistem na necessidade de problematizar o que seriam as migrações forçadas, já que o elemento da força corresponde a experiências subjetivas muito heterogêneas, que vão muito além dos limites dos estudos sobre refugiados e das pesquisas sobre tráfico de seres humanos. O que, importante destacar, "não diminuiu a necessidade de identificar e descrever com exatidão as condições específicas de migração forçada, a fim de moldar meios eficazes de proteção jurídica e humanitária” (Mezzadra, 2015, p. 12).

${ }^{9}$ A partir de estudo de caso que realizaram no Iraque e no Afeganistão. Novelli \& Cardoso (2008) mencionam o caso da USAID, agencia de ajuda internacional do governo estadunidense que tem estado presente na reconstrução de diversos aspectos dos países em situações de conflitos; e, entre suas ações, aumentaram consideravelmente os programas voltados especificamente para educação. Mencionam, por exemplo, o fato de esses programas estarem respondendo ao objetivo maior de moderar a intolerância radical e as ideologias antiocidentais. A mesma agência estaria pedindo atenção na ação local para que fosse explicitado aos moradores que as crianças recebiam vacinas graças à "cortesia” do governo dos EUA. 
Essas duas grandes categorizações coexistem com uma série de categorias disponíveis, que terminam por expressar a maneira como se nomeiam e se classificam os não nacionais, em geral em função das razões do processo migratório - como é o caso dos refugiados, solicitantes de refúgio, deslocados internos, apátridas, asilados, exilados. Estas são muitas vezes atribuídas pela legislação vigente nos âmbitos internacional e nacional. O próprio Estado vai determinar quem é nacional - e, portanto, quem não é, de acordos com critérios próprios de aquisição da nacionalidade. Outras, no entanto, são classificações cunhadas por agências multilaterais e reproduzidas por outros setores incluindo a academia, que terminam por legitimar uma terminologia como dada.

A própria palavra "migrante" não possui uma definição universal. O uso mais comum é o estabelecido pela Organização Internacional das Migrações (OIM), que define migrante como qualquer pessoa que se muda de seu lugar de residência habitual a outro - cruzando fronteiras ou dentro de um mesmo Estado. E explicita que essa definição independe do status jurídico da pessoa, se o movimento foi voluntário ou não, quais as causas desse movimento, e qual a duração da estadia. Evidentemente escapam os projetos de vida circulares, que vão e vem, os retornos múltiplos, as pessoas que vivem em muitos países ao mesmo tempo. Cernadas (2015) chama a atenção para a construção da categoria específica dos "migrantes econômicos", para o autor um conceito reducionista e equivocado, além de juridicamente inexistente, que acabou sendo usando de maneira antagônica aos refugiados e, dessa forma, com profundas implicações políticas e práticas. Quais seriam os elementos que definem a migração econômica, as normas que a regulam, os direitos dessas pessoas e as obrigações dos Estados? A OIM, por exemplo, considera como "migrante econômico" as pessoas que, tendo deixado seus lugares de residência habitual, buscam melhorar seu nível de vida em outro país. Teria abandonado seu país voluntariamente, e distingue-se, por oposição, do refugiado, que busca proteção ao fugir da perseguição ou violência.

Por sua vez, a categoria do refúgio é bastante consolidada em âmbito jurídico, tendo como um esteio a Convenção de Genebra de $1951^{10}$, que estabelece a definição clássica de refugiado como alguém que "temendo ser perseguida por motivos de raça, religião, nacionalidade, grupo social ou opiniões políticas, se encontra fora do país de sua nacionalidade e que não pode ou, em virtude desse temor, não quer valer-se da proteção desse país". Assinada no contexto do pós guerra, a origem deste histórico instrumento internacional relacionava-se à necessidade de proporcionar aos estrangeiros uma proteção específica, relacionada sobretudo ao desaparecimen to de seu Estado de origem no contexto dos significativos deslocamentos de pessoas após a Segunda Guerra Mundial, em especial pessoas que vinham da Europa Central e do Leste.

Mais tarde, em âmbito regional de América Latina e Caribe, a Declaração de Cartagena de 1984 buscava expandir os contornos da definição dada pela Convenção de 1951, e incluiu no entendimento das causas do refúgio a ameaça à vida, segurança ou liberdade, desencadeada pela "violência generalizada, agressão estrangeira, conflitos internos, violação maciça dos direitos humanos ou outras circunstâncias que tenham perturbado gravemente a ordem pública".

Se, por um lado, temos um expressivo e crescente número de pessoas forçadas a saírem de seus países pelas mais diversas perseguições, por outro é também crescente o número de pessoas que permanecem sem encontrar um novo Estado que as acolha e garanta a sua proteção. Para além da crescente dificuldade de se deslocar pelo mundo, por conta das fronteiras cada vez mais fechadas e dos muros levantados para impedir a chegada dos não desejados, a definição de refúgio tem sido majoritariamente interpretada de forma restritiva. Muitos processos de análise da concessão de

${ }^{10}$ Com o tempo e a emergência de novas situações geradoras de conflitos e perseguições, foi preparado um Protocolo relativo ao Estatuto dos Refugiados, que entrou em vigor em 1967. A Convenção e o Protocolo são os principais instrumentos internacionais estabelecidos para a proteção dos refugiados. 
refúgio terminam por desqualificar as situações de risco e ameaça experimentadas pelos solicitantes (Menezes \& Reis, 2014).

Como complementa Fassin (2011), num cenário de desconfiança, muito mais é exigido para que se tornem refugiados. Vão surgindo aparatos para escrutinar a verdade do que é narrado pelo solicitante de refúgio, que muitas vezes não tem às mãos provas concretas, o que leva muitos, lembra Bartlett (2015), a perseguir essa condição na forma como apresentam a si mesmos. A grande maioria dos casos é rejeitada e termina sendo incluída na categoria dos indocumentados. "Isso irá então confirmar empiricamente a convergência das políticas de migração e asilo, a despeito da afirmação oficial do contrário", diz Fassin (2011).

Ao lado do "refugiado", que é a pessoa que portanto cruzou a fronteira, provou sua situação de risco e recebeu do Estado receptor (soberano) esse status, é criada a figura do "deslocado forçado", que seria aquele/a que não cruza a fronteira: pode ter as mesmas razões, mas permanece dentro do território nacional. Para esse contingente, cria-se o chamado sistema de proteção dos deslocados internos, que desde 1970 passa a ficar também sob responsabilidade do ACNUR.

Outra categoria comumente encontrada na literatura, à qual corresponde um corpo jurídico na esfera internacional, é a de apátridas. À definição de apátridas corresponde a ausência de nacionalidade, enunciado simples que, no entanto, remete a complexas discussões sobre a atribuição de nacionalidade e seu vínculo com o exercício da cidadania no âmbito do Estado-Nação (Bertino \& Sala, 2018) ${ }^{11}$. De acordo com o ACNUR, são cerca de 10 milhões de pessoas em todo o mundo nestas condições, categoria que começa a ser problematizada a partir dos apátridas que se movem, sobretudo cruzando fronteiras.

Em que pese o reconhecimento jurídico das categorias acima, a figura que ganha mais atenção nos discursos públicos é a dos migrantes em situação indocumentada - rotulados como irregulares, ilegais, clandestinos, sem papéis, a despeito da insistência do movimento social em pedir o não uso desses termos ${ }^{12}$. Em pesquisa sobre o a condição migratória não documentada, Waldman (2018) destaca que a circunstância experimentada por um migrante ao ingressar e/ou permanecer no país de destino fora do abrigo da regularidade jurídica é resultado de uma produção legal de padrões de exclusão e, como decorrência, de negativas de direitos. Ao contrário do que faz pensar o discurso público das multidões cruzando os muros, atravessando desertos ou arriscando a vida nos barcos, Fassin (2011) afirma que a maior parte das pessoas sem documentação são pessoas que residem há muitos anos no país onde vivem, trabalham e constituem família. Mas estão sempre em estado de precariedade, o que facilita sua condição de vulnerabilidade.

Em pesquisa no contexto estadunidense, Ryan Gildersleeve (2016) mostrou como as próprias políticas educativas tiveram papel relevante na construção da figura do estudante não

${ }^{11}$ Historicamente, com o nascimento da modernidade e do Estado-nação, forma-se um laço estreito entre nacionalidade e cidadania. A cidadania é atribuída pelo Estado, que determina as regras sobre quem é ou não cidadão e qual sua relação com a nacionalidade. E a estes cidadãos seria destinado o conjunto de direitos e liberdades (Reis, 2007, p. 36). De acordo com o contexto e processo histórico de cada país e relação com seu povo, criam-se as formas de transmissão da cidadania originária, que ficam a critério do Estado (Mezzadra, 2005, p. 98). A possibilidade que resta aos estrangeiros é a da chamada nacionalidade derivada ou naturalização, processo cujos trâmites, critérios e tempo variam de país a país. Em geral, existem alguns momentos marcados: a saída do país de origem (emigração), a entrada no país de destino (imigração), a aquisição da permissão de residência e, apenas posteriormente, a naturalização. Essa escala - os entraves, processos e direitos que os imigrantes têm em cada uma delas - varia em cada local (Benhabibb, 2004).

${ }^{12}$ Em vários países registram-se campanhas de conscientização, inclusive de natureza internacional, empreendidas por movimentos de imigrantes e ONGs que os apoiam com esse mote: "Nadie es Ilegal", "Nenhum Ser Humano é Ilegal", "No one is illegal". 
documentado. Ao analisar o regulamento para que este possa ingressar no sistema educativo, o autor conseguiu identificar a sistemática criação e representação do estudante indocumentado como uma categoria em si mesma. De maneira inter relacionada com as demais peças discursivas (discursos políticos, midiáticos etc), atribui-se a esse estudante características como ser alguém diferente, que deve ser vigiado, e que traz ameaça à segurança nacional. Sua permanência, nesse caso, vai depender do quanto tem um potencial visto na perspectiva do "capital humano" - nesse caso acha-se uma forma para que fique. Como lembrava Sayad (1998), quando são julgadas como necessárias, as pessoas passam a ser facilmente regularizáveis.

Concordamos com Mezzadra (2015) quando o autor propõe como imprescindível o exercício de um olhar crítico para como vem sendo produzidas e construídas as ilegalidades e clandestinidades. O que faz da migração não-autorizada um verdadeiro ato de subversão? Para Fassin (2011), o processo de produção da ilegalidade vem de mãos dadas com o processo contemporâneo de produção da racialização de imigrantes. Para ele, o processo de seleção dos imigrantes desejados versus indesejados é evidentemente mais explícito nos mecanismos de controle de fronteiras, depois de acesso à permanência, residência e finalmente naturalização. Mas, mesmo os naturalizados, reforça, serão lembrados o tempo todo de sua condição. Para o autor, finalmente, a produção de ilegalidade é seletiva e tem sido chamada de criminalização racial de migrantes.

As classificações disponíveis, portanto, requerem um olhar distanciado e a leitura do conjunto mostra a porosidade de cada uma dessas categorias ou nomenclaturas. Na prática, essas classificações se misturam (Derderian \& Schochaert, 2009) ${ }^{13}$, ao mesmo tempo em que causam divisões artificiais, e qualquer que seja a resposta dos Estados e da comunidade internacional deve considerar-se esse fato - caso contrário será inócua.

Num mesmo sentido, Catherine Wihtol de Wenden (2016) enfatiza no que chama de "novas migrações" a diversidade sobreposta das causas de partida (crises políticas, econômicas, ambientais), dos itinerários (migrações por etapas, trânsito, retorno, circulares, bi ou multipolares), bem como da permeabilidade entre categorias: o mesmo migrante pode, em última instância e a depender das circunstâncias, ser nomeado de solicitante de refúgio e logo em seguida de indocumentado, de deslocado ou trabalhador, já que as novas linhas divisórias, entre a migração "sofrida" e a migração desejada num determinado contexto (Franguiadakis, 2016) se entrecruzam. Assim, as agências que tratam do tema e a literatura especializada foram levadas a falar em "fluxos mistos", que incluem refugiados, solicitantes de refúgio, os nomeados de "migrantes econômicos", crianças desacompanhadas, migrantes ambientais, deslocamentos forçados por desastres naturais, vítimas de tráfico, entre outros (Leão, 2011), reconhecendo contudo as dificuldades de identificação e proteção daquelas pessoas que sofrem perseguição e que, por isto, requerem proteção internacional.

Em nosso conjunto de documentos analisados sobre políticas educativas internacionais sobre a temática da migração e refúgio, encontramos essencialmente as duas classificações mais usadas: ou se fala em migrante ou imigrante (por vezes econômicos), ou em refugiados/as, não necessariamente seguindo a definição jurídica ou o reconhecimento desse status em cada país, mas usa-se como um sinônimo de sujeitos dos deslocamentos forçados de maneira geral, da pessoa que não teve escolha senão sair de uma situação de perseguição, violência ou conflito. Em alguns poucos casos, surge a menção a deslocados internos com esse mesmo sentido. Demais categorias e nuances entre elas não existem nesse conjunto, e naturaliza-se a divisão mais tradicional e recorrente entre migrantes voluntários ou involuntários, sendo que estes últimos estão muito mais presentes no conjunto, parecem gerar mais interesse dos agentes internacionais que atuam com políticas

${ }^{13}$ Constatação das autoras a partir da análise da experiência na organização Médico Sem Fronteiras em campos de refugiados. 
educativas no âmbito global. O documento Marco de Ação da Educação 2030, como dissemos anteriormente fruto de negociação multilateral, reflete esse fato: menciona uma vez a palavra "migrante", no contexto de que ninguém pode ficar de fora de uma educação inclusiva ao longo da vida ${ }^{14}$, enquanto a menção aos refugiados surge ao menos uma dezena de vezes: "É essencial manter a educação durante as situações de emergência, conflito e posteriores aos conflitos e desastres, e satisfazer às necessidades educativas dos deslocados internos e refugiados"15 (Marco de Ação E2030, UNESCO, 2015, Art. 56).

O mais recente informe "Migração, deslocamento e educação: construir pontes, não muros", (UNESCO, 2018), que trata da temática de maneira bastante mais abrangente, é um exemplo muito ilustrativo das classificações nas quais por fim são reforçadas as divisões entre as migrações internacionais (em que constariam "as pessoas buscam melhores condições de vida e trabalho"), os deslocamentos forçados (onde estariam os "vulneráveis que vem das partes mais pobres e carentes do mundo") e ainda nesse caso traz uma terceira vertente, separada das anteriores e nomeada de "mobilidade internacional", esta apresentada como fruto de "um mundo cada vez mais globalizado", em que "jovens estudam no exterior, e profissionais qualificados buscam oportunidades de emprego além das fronteiras, a fim de exercer seus talentos" (UNESCO, 2018, p. 34). Ou seja, esta última seria a única vertente apresentada de maneira positiva, enquanto as demais seriam o problema, apresentado ao lado das dificuldades para os que a vivem (de lidar com a burocracia e discriminação), e dos desafios para os Estados (de lidar com a diversidade, proporcionar infraestrutura, formação docente específica por exemplo).

Esta terceira categoria leva a uma fundamental reflexão para os propósitos deste texto, expressando um reforço nos muitos mecanismos que, como dissemos no início, aclamam a mobilidade internacional como símbolo de uma sociedade aberta e moderna, ao mesmo tempo em que desenvolvem mecanismos de repulsão àquela migração que não é bem-vinda. Um perfil de estudantes cujo deslocamento é visto como positivo, como um dado que irá contribuir para sua vida e para o mundo, em oposição aos outros que de fato gerariam um desafio, ou um problema a enfrentar-se. Como dizem Swanson e Gamal (2018), cultiva-se a ideia do "cidadão global" no discurso político e nos esforços institucionais acionando, para isso, a importância da mobilidade internacional de certos grupos, ao mesmo tempo em que se deslegitima a circulação de outros.

Esse dado revela, assim, uma dimensão central do debate sobre as circulações internacionais contemporâneas, cuja dinâmica dificulta, obstaculiza e criminaliza a viagem para parte das pessoas que a realizam (Ventura, 2016). A dinâmica requer, evidentemente, outra lente analítica, que supere o olhar simplificado da falsa oposição entre "nativos" e "não nativos", mas aplicando portanto uma ótica interseccional, ou seja, entender como as diferentes desigualdades e sistemas de opressão como de classe, raça-etnia e gênero -, se relacionam numa determinada localidade, como influem nas trajetórias migratórias e na vida das pessoas que migram em cada contexto, num diálogo com o que Brah (2011) nomeou como "espaços da diáspora", desafiando a uma percepção sobre como tais eixos de diferenciação se articulam e desarticulam, marcando e sendo marcadas pela complexa rede de poder em que estão inseridos.

\section{A Crise e a Vítima da Crise}

14 “Todas las personas, sea cual sea su sexo, edad, raza, color, origen étnico, idioma, religión, opinión política o de otro tipo, origen nacional o social, posición económica o nacimiento, así como las personas con discapacidad, los migrantes, los pueblos indígenas y los niños y jóvenes, en particular los que se encuentran en situación de vulnerabilidad o de otro tipo, deben tener acceso a una educación de calidad inclusiva y equitativa y oportunidades de aprendizaje a lo largo de la vida".

15 Tradução Nossa. 
Nosso segundo eixo analítico para o referido conjunto de documentos que tratam da temática da educação e refúgio nas políticas educativas globais diz respeito à construção e ao reforço para a figura da vítima, dimensão muito presente nos materiais lidos, sobretudo os que lançam luz sobre os deslocamentos forçados. A narrativa acompanha aquela emergente após o ano de 2015, quando se observa, em âmbito mundial, a ascensão de um discurso que remete a uma "crescente e incontrolável crise migratória". O crescimento da visibilidade mediática das jornadas arriscadas como os barcos que diariamente cruzam o Mar Mediterrâneo com pessoas tentando entrar na Europa, ou aquelas que arriscam suas vidas tentando cruzar a fronteira entre México e Estados Unidos, os números sendo apresentados sempre como novos e surpreendentes recordes, ajudam a passar a sensação de uma avalanche migratória fora de controle, com necessidade de soluções emergenciais.

De todo modo, em 2015 a própria ONU falava na "maior crise de refugiados da história" após a segunda guerra mundial, discurso que se pulverizou rapidamente por várias camadas e esferas, sendo reproduzido nos âmbitos governamentais, mediático e também acadêmico ${ }^{16}$, inclusive com expressão em âmbito local ${ }^{17}$. Dois contrapontos são importantes de serem feitos nesse sentido: um primeiro diz respeito às médias mundiais, que escondem a natureza concentrada dos deslocamentos. Como lembra Castles (2010), em algumas areas de origem estabeleceram-se culturas de emigração, enquanto a presença de imigrantes é concentrada em alguns países e cidades particularmente. E o outro ponto diz respeito às situações humanitárias em localidades específicas, com o aumento da chegada de solicitantes de refúgio, por exemplo, o que requer respostas urgentes e concretas nestes locais.

Em todo caso, o uso generalizado da ideia de crise remetia à narrativa de uma "invasão incontrolável de pessoas", de modo que implicou numa série de consequências, ajudou a criar uma sensação de emergência e, assim, justificar práticas próprias de Estados de exceção (Cernadas, 2016; Backwewell, 2008). As repercussões envolveram uma sobreposição de respostas humanitárias com o acirramento de políticas e medidas concretas que tratam aquele que vem de fora como uma possível ameaça, como um potencial inimigo.

Os documentos analisados elaborados após 2015 dialogam de maneira direta com esse contexto. Alguns trazem a palavra "crise" já no título ${ }^{18}$, e a expressão "crise de refugiados" é reproduzida amplamente com o destaque para a produção de vítimas, incluindo crianças. $\mathrm{Na}$ narrativa, aparece ainda o complemento: foram afetados pela crise e agora estariam também vítimas da impossibilidade de estudar. Propõe-se um deslocamento da crise do refúgio à crise da educação para pessoas refugiadas e nota-se um insistente reforço retórico na importância da oportunidade educativa para essas populações. Ao invés da mobilização do discurso da educação como um direito humano (Magalhães \& Schilling, 2012), incorre-se a um amplo espectro de justificativas, como se

${ }^{16}$ Pesquisas recentes de percepção ajudam a compreender como a imagem que se tem das populações imigrantes são distorcidas. Estudo de Alesina, Miano e Stantcheva (2018) mostrou que nos Estados Unidos e em diversos países europeus superestima-se suas respectivas populações imigrantes - e estão longe de conhecer suas características. Superestima-se o número de muçulmanos e subestima-se o de cristãos. Da mesma forma, acredita-se que sejam menos qualificados do que são, mais pobres e dependentes do estado de bem-estar.

${ }^{17}$ Com repercussão inclusive na visão da demanda por escolas. Em São Paulo, por exemplo, uma manchete dizia 'Onda estrangeira' força adaptação de escolas da rede municipal de SP (Folha de S. Paulo, 16 de Ago 2017).

18 Dos originais: Left Behind - Refugee Education in Crises (ACNUR, 2017); Investing in the Crisis: private participation in the education of Syrian Refugees (EI, 2017); Syria Crisis: Education Interrupted: Global Action to rescue the schooling of a Generation (ACNUR et all, 2013). 
fosse necessário um esforço de convencimento para o fato de o processo educativo ser importante para eles e elas, e sobretudo para que possam contribuir com suas sociedades de origem e destino.

Decorre dessa descrição outro apelo humanitário comum de ser encontrado no conjunto documental: como se, perdida a capacidade de nos identificarmos com eles e elas, o esforço fosse o de criar uma conexão, mostrando como aquela pessoa foi vítima da circunstância, como tinha uma profissão reconhecida, remuneração digna, status etc, como poderia "ser um de nós". Inclusive nos materiais elaborados para crianças - nota-se um esforço de mostrar, através das histórias de vida de outras crianças, que estas poderiam ser seus pares, que tiveram de fugir, que sentiram medo. São pessoas vítimas de conflitos e desastres naturais, que guardam um trauma, que perderam tudo o que tinham, reforçam os textos.

O mero esforço de mostrar-se que "são um de nós" deve ser posto como objeto de reflexão. Por que é necessário? Possivelmente o esforço venha em oposição ao que autores como Zygmunt Bauman, Judith Butler ou Achille Mbembe vêm refletindo no campo das vidas supérfluas, das vidas que valem menos, como um traço marcante de nosso tempo. Mbembe (2017) comenta justamente como as nações ocidentais continuam a mobilizar o racismo, que passa por todas as histórias de negação de imigrantes, de nacionais que devem continuar sendo vistos e chamados de imigrantes, de fronteiras que devem ser restauradas, de intrusos, de inimigos, histórias de segurança nacional, de tradições, infinitas histórias que se reciclam.

Por outro lado, Bauman (2017) comenta que o fenômeno nomeado como a "tragédia dos refugiados" estaria se aproximando de modo gradual, porém inexorável, do que chama de ponto de fadiga. Uma sucessão de fotos de muros e cercas de arames farpados parecem não sensibilizar muito mais, diz o autor, as imagens de graves e violentos episódios humanitários costumam gerar acirradas mobilizações de setores muitos diversos que, no entanto, se arrefecem com o passar do tempo. "Infelizmente, o destino dos choques é transformar-se na rotina tediosa da normalidade - e o dos pânicos é desgastar-se e desaparecer da vista e das consciências, envoltos no véu do esquecimento" (Bauman, 2017, p. 8). Ou seja, tendem a ser esquecidas, mesmo em momentos de endurecimentos dos discursos, políticas e práticas que lhes atacam frontalmente, ou que a própria solidariedade torna-se alvo de regulação e criminalização. ${ }^{19}$

Fassin lembra que "a mudança da legitimidade, de protecionista para uma obrigação humanitária, ocorreu como um remédio parcial para a perda de credibilidade de quem busca asilo" (Fassin, 2013, p. 20). Com o apelo midiático voltado para as questões humanitárias, as decisões terminam por serem respostas às demonstrações públicas de compaixão e não pelos direitos inalienáveis da pessoa que solicita proteção no exílio, o que é notável sobretudo no caso dos refugiados, solicitantes de refúgio e sujeitos das migrações forçadas, mas também se aplica a imigrantes de maneira geral a depender do discurso mobilizado. Assim, ou exalta-se a compaixão, ou são vistos como suspeitos. No limite, a dupla invocação que se faz às pessoas que cruzam fronteiras - ora humanitária e ora de segurança - não teria por consequência uma suspensão do direito?

Nesse ponto, em busca de uma forma de ver a relação com o sofrimento do outro que supere a piedade e a compaixão sem, no entanto, romper o vínculo com a solidariedade como uma forma de estar e partilhar o mundo, parece-nos oportuno finalizar esta reflexão com uma breve menção à ética da solicitude de Paul Ricoeur. Para o filósofo, na busca da relação com o outro, a questão da partilha, do dar e receber, não é uma relação simétrica, dado que as condições e

${ }^{19}$ A prática foi noticiada na França (posteriormente revogada), na Espanha, Estados Unidos e Niger. As normas variam no conceito de "ajuda a imigrantes" (dar informações, encorajar, alojar, transportar) e na punição (de multas a prisão). Por exemplo este interessante compilado disponível no Portal MigraMundo. Disponível em http://migramundo.com/delitos-de-solidariedade-veja-paises-que-criminalizam-a-ajuda-aimigrantes/. Visitado em 14 de Agosto de 2018. 
possibilidades das pessoas envolvidas nunca serão iguais - condições que extrapolam as materiais. Um elemento central dessa dissimetria, diz ele, é a solicitude, que responde ao campo da ética mais do que à obrigatoriedade de uma norma. Como diz Martini (2016), trata-se da simpatia de um ser humano que age e sofre e cuja iniciativa pode ser a compaixão ou a partilha da alegria e da dor. Essa simpatia, diz a autora, não se confunde com piedade ou com qualquer outro sentimento - o que se pode compartilhar é nossa fragilidade, nossa contingência, reconhecida por cada um. A solicitude está relacionada ao fato de que receber é o mesmo que dar, como responsabilidade decorrente do reconhecimento do outro pelo si mesmo e do outro como a si mesmo, sempre em nossa condição comum de seres vulneráveis.

\section{Considerações Finais}

Por meio da leitura de um conjunto de documentos recentes sobre educação, imigração e refúgio, foi possível perceber como o campo da produção da política educativa global também participa e interage com os principais debate migratórios, reforçando as construções em torno de uma ideia de sujeitos individuais e coletivos das mobilidades internacionais.

Um primeiro ponto a destacar-se relaciona-se à maneira como tal conjunto não apenas reforça a divisão tradicional entre as migrações voluntárias e forçadas quando se referem às populações migrantes e refugiadas nas escolas, mas sobretudo como a partir dele emerge também o olhar para a mobilidade internacional de certos grupos de estudantes que seriam o símbolo de uma sociedade aberta e moderna, em detrimento dos demais, cuja circulação é deslegitimada. Naturalizase, assim, um tratamento das migrações internacionais como um "problema a resolver-se" - exceto para um seleto grupo que estaria autorizado a circular.

Como dissemos anteriormente, a dinâmica requer, evidentemente, outra lente analítica, que supere o olhar simplificado da falsa oposição entre "nativos" e "não nativos", mas aplicando portanto uma ótica interseccional, ou seja, entender como as diferentes desigualdades e sistemas de opressão - como de classe, raça-etnia e gênero -, se relacionam numa determinada localidade, como influem nas trajetórias migratórias e na vida das pessoas que migram em cada contexto.

Por outro lado, o reforço na construção da vítima se mostra fortemente presente, acompanhando a narrativa sobre a chamada crise migratória ou de refugiados. Os fluxos migratórios contemporâneos são apresentados como um "desafio novo", frutos de "uma crise", e não como um dado constitutivo do mundo, do ser humano e suas culturas, do que somos hoje. Nesse sentido, uma notável ausência nos documentos analisados é a perspectiva dos muitos e diversos movimentos e coletivos de imigrantes, que poderiam complexificar essa narrativa, mostrar outras formas de estar no mundo, além de compartilhar reflexões, estratégias e propostas que esses próprios grupos vem dando para as situações adversas.

Finalmente, merece menção o deslocamento da perspectiva da educação como um direito humano fundamental - o que a nosso ver seria o ponto de partida, aparece em geral tangencialmente, como um dado a mais, de modo que faz-se necessário uma série de justificativas extras, um relevante esforço de convencimento, para o compromisso que no limite deveria ser dado, a realização de um direito. O reforço retórico na necessidade e importância da educação, mostrando a todo tempo suas vantagens, indica a urgente necessidade de trazer a narrativa dos direitos humanos para o primeiro plano, como o conjunto mobilizador por si mesmo. Por que não é óbvio que para eles e elas a oferta educativa deve ser um dado? Este parece ser um problema central, o que mostra o quão atual e vigente é ainda a reflexão arendtiana sobre não nacionais como um caso paradigmático para a discussão da aplicabilidade dos direitos humanos universais afirmados historicamente. 
Como dissemos anteriormente, as políticas e debates globais não possuem uma influência determinante nem uniforme, não circulam de maneira previsível. Vão negociar e interagir com as múltiplas vozes, instituições e atores locais. Mas os discursos, sempre construídos em interação com as práticas, estão presentes, são concretos e circulam através de fronteiras pouco estáveis.

\section{Referências}

ACNUR. (2017). Left behind - Refugee education in crises. https://www.unhcr.org/left-behind/.

ACNUR. (2012). 2012-2016 Education strategy. https://www.unhcr.org/protection/operations/5149ba349/unhcr-education-strategy-20122016.html.

ACNUR. (2011). Refugee education: Global review. https://www.unhcr.org/research/evalreports/4fe317589/refugee-education-global-reviewsarah-dryden-peterson-november-2011.html.

Alesina, A., Miano, A., \& Stantcheva. S. (2018) Immigration and redistribution. (NBER Working Paper Series). National Bureau of Economic Research. https://www.nber.org/papers/w24733.

Anderson, B. (2008). Comunidades imaginadas. Companhia das Letras.

Arendt, H. (1989). Origens do totalitarismo - anti-semitismo, imperialismo, totalitarismo. Companhia das Letras.

Backwell, O. (2008). Keeping them in their place: The ambivalent relationship between development and migration in Africa. Third World Quarterly, 29(7), 1341-1358. https://doi.org/10.1080/01436590802386492

Ball, S. (2001). Diretrizes Políticas Globais e Relações Políticas Locais em Educação. Currículo sem Fronteiras, 1(2), 99-116.

Bartlett, L. (2015). Migration and education: sociocultural perspectives. Educação \& Pesquisa, São Paulo, 41, 1153-1170. https://doi.org/10.1590/S1517-9702201508144891

Bauman, Z. (2017). Estranhos à nossa porta. Jorge Zahar.

Benhabibb, S. (2004). The tights of others - Aliens, residents and citizens. Cambridge University Press.

Bertino, J., \& Sala, J.B. (2018). Migraçõos forçadas: Categorização em torno de sujeitos migrantes In L. L. Jubilut, F. M. D. Frinhani \& R. O. Lopes (Orgs.), Migrantes forçados: Conceitos e contextos. Editora da UFRR.

Brah, A. (2011). Cartografías de la diáspora: Identidades en cuestión. Traficantes de Sueños.

Castles S. (2010). Entendendo a migração global. Uma perspectiva desde a transformação social. Revista Interdisciplinar da. Mobilidade. Humana., 35, 11-43.

Cernadas, P. C. (2016) A linguagem como instrumento de política migratória. SUR Revista Internacional de Direitos Humanos, 13(23), 97-112.

Cogo, D., \& Souza, M.B. (2013). Guia das migraçoes transnacionais e diversidade cultural para comunicadores Migrantes no Brasil. Institut de la Comunicación-UAB/Instituto Humanitas - Unisinos.

Croso, C., \& Magalhães, G. M. (2016). Privatização da educação na América Latina e no Caribe: Tendências e riscos para os sistemas públicos de ensino. Educação \& Sociedade, 37(134), 17 33. https://doi.org/10.1590/ES0101-73302016157622

Dryden-Peterson, S. (2011). Refugee education - A global review. UNHCR.

Dryden-Peterson, S. (2016). Policies for education in conflict and post-conflict reconstruction. In: K Mundy, A. Green, B. Lingard, B. \& T. Verger, The handbook of global education policy. John Wiley \& Sons. https://doi.org/10.1002/9781118468005.ch10 
Évora, I. (2015). A migração cabo-verdiana e as ciências sociais: Uma leitura crítica. In: I Évora \& P. J. Laurent (Orgs), Ciências sociais em Cabo Verde. Quem somos? Para onde vamos? (pp. 110-127). EdiçõesUni-CV.

Fassin, D. (2011). Policing borders, producing boundaries. The governmentality of immigration in dark times. Annual Review of Antropology, 40, 213-226. https://doi.org/10.1146/annurevanthro-081309-145847

Foucault, M. (2008). A ordem do discurso: aula inangural no Collège de France, de 2 de dezembro de 1970. Edições Loyola.

Franguiadakis, S. (2016). A pragmática do asilo: Política de acolhimento e os limites do espaço público. In: J. A. P. Gediel \& G. G. Godoy, Refúgio e hospitalidade. Kairós Edições.

Gamal, M., \& Swanson, D. (2018). Alterities of global citizenship: Education, human rights, and everyday bordering. Justice, Power and Resistance, 2(2), 357-388.

Gildersleeve, R. (2017). Making and becoming the Undocumented and the Illegal: Discourses of immigration and American higher education policy. Education Policy Analysis Archives, 25 (31). https://doi.org/10.14507/epaa.25.2286

Herrera, G. (2017). Migraciones internacionales Contemporaneas - Violencia y desigualdad global. Megafon - La Batalla de las Ideas, 1(14).

Koltai. C. (Org.). (1998). O estrangeiro. Escuta-Fapesp.

Leão, R. Z. R. (2011). CONARE: Balanço de seus 14 anos de existência. In: G. A. Almeida, A. R. Carvalho \& C. Rodrigues (Orgs.). 60 anos de ACNUR: Perspectivas de futuro (pp. 69-92). Editora CL-A Cultural.

Magalhães, G. M. (2019). Entre Muros e Passagens: Imigração, refúgio e mobilidades no debate educativo, fragmentos do global ao local. (Tese de Doutorado). Faculdade de Educação, Universidade de São Paulo, São Paulo.

Magalhães, G. M., \& Schilling, F. (2012). Imigrantes da Bolivia na escola em São Paulo: Fronteiras do Direito à Educação. Pro-Posições (UNICAMP, impresso), 23, 43-64. https://doi.org/10.1590/S0103-73072012000100004

Martini, R. M. F. (2016). Paul Ricoeur: A ética da solicitude questiona a educação. Pro-Posições (UNICAMP. Impresso), 27(2), p. 235-252. https://doi.org/10.1590/1980-6248-2015-0016

Mbembe, A. (2017). Politicas daiInimizade. Antígona.

Mezzadra, S. (2015). Multiplicação das fronteiras e práticas de mobilidade. REMHU - Revist. Interdisciplinar de Mobilidade Humana, 44, 11-30. https:// doi.org/10.1590/198085852503880004402

Mezzadra, S. (2005). Derecho de Fuga-Migraciones, ciudadanía y globalización. Proyecto Traficante de Sueños.

Mundy, K. Green. A., Lingard, B., \& Verger, T. (2016). The handbook of global education policy.: John Wiley \& Sons. https://doi.org/10.1002/9781118468005

Novelli, M., \& Cardozo, M. T. A. (2008). Conflict, education and the global south: New critical directions. International Journal of Educational Development, 4(28), 473-488. https://doi.org/10.1016/j.ijedudev.2008.01.004

OCDE. (2018). The resilience of students with migrant background, factors that shape well being. ehttp://www.oecd.org/education/the-resilience-of-students-with-an-immigrantbackground-9789264292093-en.htm.

Organização Internacional papa as migraçãos. (2019). La migración y la Agenda 2030: Guía para Profesionales. http://publications.iom.int/system/files/pdf/sdg_es.pdf.

Ricoeur. P. (1996). Sí mismo como otro. Siglo Veintiuno Editores. 
Santamaría, E. (2002). Inmigración y barbarie. La construcción social y política del inmigrante como amenaza. Papers, 66, 59-75.

Santamaria, E. (2011). Lugares comuns e estranhamento social: a problematização sociológica das mobilidades migratórias. In: J. Larrosa \& C. Skliar (Orgs.). Habitantes de Babel: Politicas e poéticas da diferença. Autêntica.

Sayad, A. (1998). A imigração: Ou os paradoxos da alteridade. Universidade de São Paulo.

UNESCO (2015). Marco de Ação da Educaşão 2030. http://www.unesco.org/new/pt/brasilia/about-this-office/singleview/news/education_2030_incheon_declaration_and_and_framework_for_ac/.

UNESCO. (2018). Migração, deslocamento e educação: construir pontes, não muros. https://unesdoc.unesco.org/ark:/48223/pf0000265996_por.

UNICEF. (2017). Education Uprooted: for every migrant, refugee or displaced child, education. https://www.unicef.org/publications/index_100817.html.

UNICEF. (2018). Uprooted: The growing crisis for refugee and migrant children. https://www.unicef.org/publications/index_92710.html.

Ventura, D. (2016). Impacto das crises sanitárias internacionais sobre os direitos dos migrantes. SUR Revista Internacional de Direitos Humanos, 23.

Waldman, T. (2016). Nem clandestinos, nem ilegais: c Cnstruindo contornos para uma definição da condiçãomigratória não documentada no Brasil. (Tese de Doutorado) - Faculdade de Direito, Universidade de São Paulo, São Paulo.

Wenden, C.W. (2016). New migrations. SUR Revista Internacional de Direitos Humanos, 23. 


\section{Sobre as Autoras}

Giovanna Modé Magalhães

Faculdade de Educação / Universidade de São Paulo

giovannamode@gmail.com

https://orcid.org/0000-0001-7404-1436

Mestre e Doutora em Sociologia da Educação pela FEUSP, coordenadora de políticas e programas da Campanha Latino-Americana pelo Direito à Educação (CLADE).

\section{Flávia Schilling}

Faculdade de Educação / Universidade de São Paulo

flaviaischilling@gmail.com

https://orcid.org/0000-0001-5126-8507

Doutora em Sociologia. Professora Associada da FEUSP, Pesquisadora do CNPq e vice-

coordenadora do Grupo de Pesquisas sobre Direitos Humanos, Memória, Política e Democracia do Instituto de Estudos Avançados da USP.

\section{Sobre as Editoras}

\section{Ana Lorena Bruel}

Universidade Federal do Paraná

analorena@ufpr.br

ORCID: https://orcid.org/0000-0001-7978-5805

Professora pesquisadora no Núcleo de Políticas Educacionais e do Programa de Pós-Graduação em Educação da Universidade Federal do Paraná (Brasil). Professora visitante na Universidade de Bordeaux (França) entre 2018 e 2019 com financiamento CAPES Processo no 88881.172843/201801.

\section{Isabelle Rigoni}

Institut Nacional Sepérieur de Formation et de Recherche pour l'Éducation des Jeunes Handicapés et les Enseignements Adaptés (INSHEA, Grhapes)

isabelle.rigoni@inshea.fr

Professora de Sociologia no INSHEA (França), pesquisadora no Laboratório Grhapes e especialista da Comissão Europeia.

\section{Maïtena Armagnague}

Univerisité de Genève (Unige, FPSE, EduMiJ)

maitena.armagnague@gmail.com

Professora de Sociologia no INSHEA (França) e professora associada na Univerisité de Genève (Suíça), pesquisadora no Laboratório Grhapes e pesquisadora associada ao Centre Émile Durkheim e ao MIGRINTER. 


\section{Dossiê Especial \\ Migrações Internacionais e o Direito à Educação: \\ Desafios para o Enfrentamento de Desigualdades pelas Políticas dos \\ Sistemas de Ensino}

\section{arquivos analíticos de políticas educativas}

Volume 29 Número 75

24 de mayo 2021

ISSN 1068-2341

(c) () (2)

Este artigo pode ser copiado, exibido, distribuido e adaptado, desde que o(s) autor(es) e Arquivos Analíticos de Políticas Educativas sejam creditados e a autoría original atribuídos, as alterações sejam identificadas e a mesma licença CC se aplique à obra derivada. Mais detalhes sobre a licença Creative Commons podem ser encontrados em https://creativecommons.org/licenses/by-sa/4.0/. Arquivos Analiticos de Políticas Educativas é publicado pela Mary Lou Fulton Teachers College, Arizona State University. Os artigos que aparecem na AAPE são indexados em CIRC (Clasificación Integrada de Revistas Científicas, España) DIALNET (España), Directory of Open Access Journals, EBSCO Education Research Complete, ERIC, Education Full Text (H.W. Wilson), PubMed, QUALIS A1 (Brazil), Redalyc, SCImago Journal Rank, SCOPUS, SOCOLAR (China).

Sobre o Conselho Editorial: https://epaa.asu.edu/ojs/about/editorialTeam

Para erros e sugestões, entre em contato com Fischman@asu.edu

EPAA Facebook (https://www.facebook.com/EPAAAAPE) Twitter feed @epaa_aape. 